\title{
A Structured Literature Review of the Epidemiology and Disease Burden of Non-Alcoholic Steatohepatitis (NASH)
}

\author{
Manca Povsic (1) $\cdot$ On Yee Wong $\cdot$ Richard Perry $\cdot$ Juliana Bottomley
}

Received: March 12, 2019 / Published online: May 7, 2019

(C) The Author(s) 2019
September 2017. Additional grey literature searches were conducted. A total of 53 references were selected; 38 were peer-reviewed and 15 were grey literature sources.

Results: NASH is estimated to affect $3-5 \%$ of the global population, most suffering from several comorbidities. Advancing fibrosis drives clinical outcomes, with approximately $20 \%$ of patients developing cirrhosis and/or HCC, the latter being a leading cause of death in NASH. A recent model predicted the 15-year survival of advanced fibrosis patients at F3 and F4 as 51.0\% and $28.4 \%$, respectively. The limited data consistently show that NASH patients experience significantly poorer QoL and higher costs compared to non-NASH patients.

Conclusion: This first broad-ranging examination of NASH literature revealed a paucity of evidence, with poor-quality, small studies found. The overwhelming impact of NASH and its patient and healthcare burden is evident. Further evidence is needed to improve our understanding of NASH, especially as fibrosis stages advance.

Funding: Gilead Science Inc.

Keywords: Burden of disease; Epidemiology; NASH; Non-alcoholic steatohepatitis

\section{INTRODUCTION}

M. Povsic $(\triangle) \cdot$ O. Y. Wong $\cdot$ R. Perry
Adelphi Values, Bollington, Cheshire, UK

e-mail: manca.povsic@adelphivalues.com

J. Bottomley

Gilead Sciences Inc., Uxbridge, Middlesex, UK
Non-alcoholic steatohepatitis (NASH) is a chronic and progressive liver disease 
characterized by the accumulation of fat in the liver (steatosis), as well inflammation [1, 2]. NASH is a progression of non-alcoholic fatty liver disease (NAFLD), an umbrella term to describe excess fat in the liver of patients who drink little to no alcohol [1]. The exact cause of NAFLD to NASH progression is unknown and is likely due to a complex interplay of environmental and genetic factors; however, certain health conditions, such as obesity, high blood pressure and diabetes, increase the risk of it developing [3, 4]. Numerous genetic, epigenetic and environmental contributors have recently been proposed as the cause of NAFLD and $\mathrm{NASH}$, including smoking and altered copper bioavailability [5-7].

$\mathrm{NASH}$ is often inaccurately described as an asymptomatic disease [8] -it presents with nonspecific symptoms, such as tiredness or developing pain in the upper right side of the abdomen, therefore the disease can progress undetected [3]. This makes the exact burden difficult to establish. However, NASH burden is increasing, parallelled by the rise of obesity and NAFLD, with an estimated one-third of NAFLD patients progressing into NASH [1]. In the UK alone, this represents approximately $5 \%$ of the population $[9,10]$. NASH can lead to liver fibrosis, with approximately $20 \%$ of all NASH patients suffering from advanced fibrosisnamely bridging fibrosis (F3) or cirrhosis (F4) $[1,11]$. Advanced fibrosis increases the disease burden in NASH significantly, leading to endstage liver disease, hepatocellular cancer (HCC), liver transplantation and death [12]. The underlying fibrosis stage is key in determining clinical outcomes and mortality, with advanced fibrosis being an independent predictor of overall and disease-specific mortality [13].

Despite its growing burden, there is a lack of effective non-invasive diagnosis tests for NASH [14]. Liver biopsy is often considered the current gold standard for diagnosis in spite of challenges associated with its accuracy, patient acceptance, safety and cost. In addition to its complex nature and difficulties in diagnosing, there are currently no approved therapies for NASH [14-16]. Understanding the epidemiology and burden of NASH is vital in establishing clear guidelines for early detection and effective therapies [17].

The current evidence base for the epidemiology and burden of disease (BoD) of NASH is very limited, with few systematic literature reviews (SLRs) available and NASH frequently reported as part of the wider NAFLD burden. To understand the unmet need in NASH, this structured literature review aimed to examine the current knowledge on NASH epidemiology and BoD, focusing on the prevalence, comorbidities, disease progression, mortality, quality of life (QoL) and economic burden. The primary objective was to understand the NASH epidemiology landscape, encompassing the broad overarching societal and economic impacts on both the individual and the healthcare system, and to identify key gaps in current knowledge to inform future research.

\section{METHODOLOGY}

A structured literature review was performed according to an agreed search protocol following the systematic principles of the Cochrane handbook for systematic reviews [18]. The following electronic databases were searched utilizing the Ovid search engine: Embase, Medline, PsycINFO and EconLit. Two independent literature searches were conducted to identify publications relating to the epidemiology and BoD of NASH. The search terms used in the search strategy utilized a combination of free-text searching and 'subject headings' to ensure that the most relevant literature was identified for review. The full search strategy is presented in Appendix A. Searches were limited to English language publications between January 2007 and September 2017.

Publications were included in the full-text review if they reported on disease burden, disease progression, epidemiology, humanistic burden, healthcare utilization or economic burden in adults with NASH only. As a result of the breadth of our overarching objectives to critique and understand epidemiological and BoD aspects of NASH, the specific detail of individual therapy and management options was not a consideration for inclusion criteria 
and evaluation in this review. In addition to NASH-focused publications, data from NAFLDfocused publications were included in this review if the reported patient population was stratified into discrete NASH and NAFLD populations, and results were reported in sufficient detail that the NASH results could be inferred or calculated.

An internet-based search using a combination of keywords was also conducted to ensure that the latest relevant abstracts and publications were captured. The search included both non-peer-reviewed publicly available information and peer-reviewed publications that may not yet be indexed in databases such as PUBMED or Embase, because of their recent publication date, or because they were published in journals that are not indexed within these databases. A grey literature search was also carried out, reviewing conference proceedings from International Society for Pharmacoeconomics and Outcomes Research (ISPOR), American Association for the Study of Liver Diseases (AASLD), European Association for the Study of Diabetes (EASD), European Association for the Study of the Liver (EASL), Paris Hepatology Conference (PHC) and 3rd Paris NASH Symposium.
This article is based on previously conducted studies and does not contain any studies with human participants or animals performed by any of the authors.

\section{RESULTS}

During the title and abstract screening, 1229 of the 1273 retrieved abstracts were excluded on the basis of defined inclusion criteria presented in the preceding section. The full text of 44 potentially relevant records was assessed and six records were excluded. The grey literature search identified 15 conference abstracts/posters and guidelines, which were deemed relevant for inclusion. In total, 53 publications (38 full-text and 15 grey literature sources) were included into the evidence base used to develop this review. A full Preferred Reporting Items for Systematic Reviews and Meta-Analyses (PRISMA) diagram is presented in Fig. 1. The publications were categorized on the basis of the type of BoD data reported as follows:

- NASH prevalence and incidence

- Comorbidities associated with NASH

- Disease progression and mortality in NASH patients

- NASH QOL

- NASH economic burden

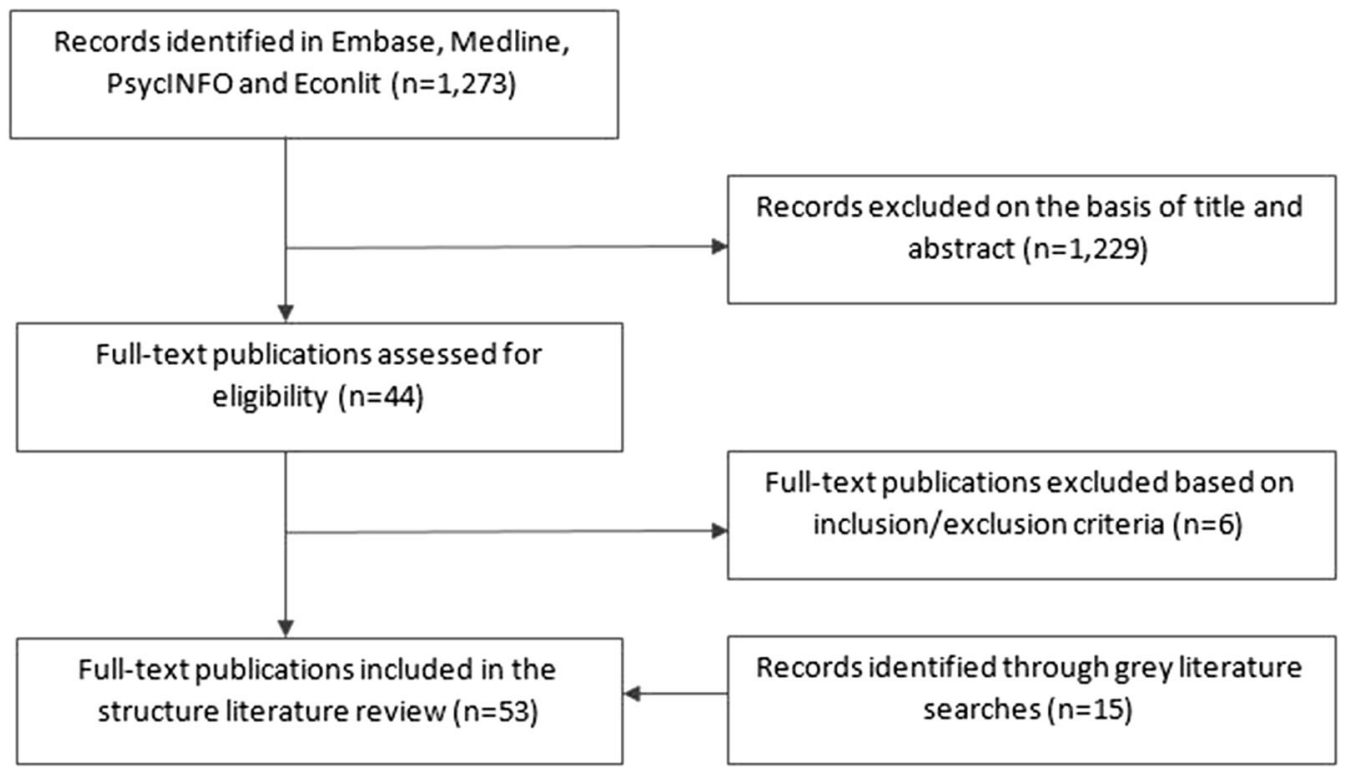

Fig. 1 PRISMA diagram of included and excluded publications 


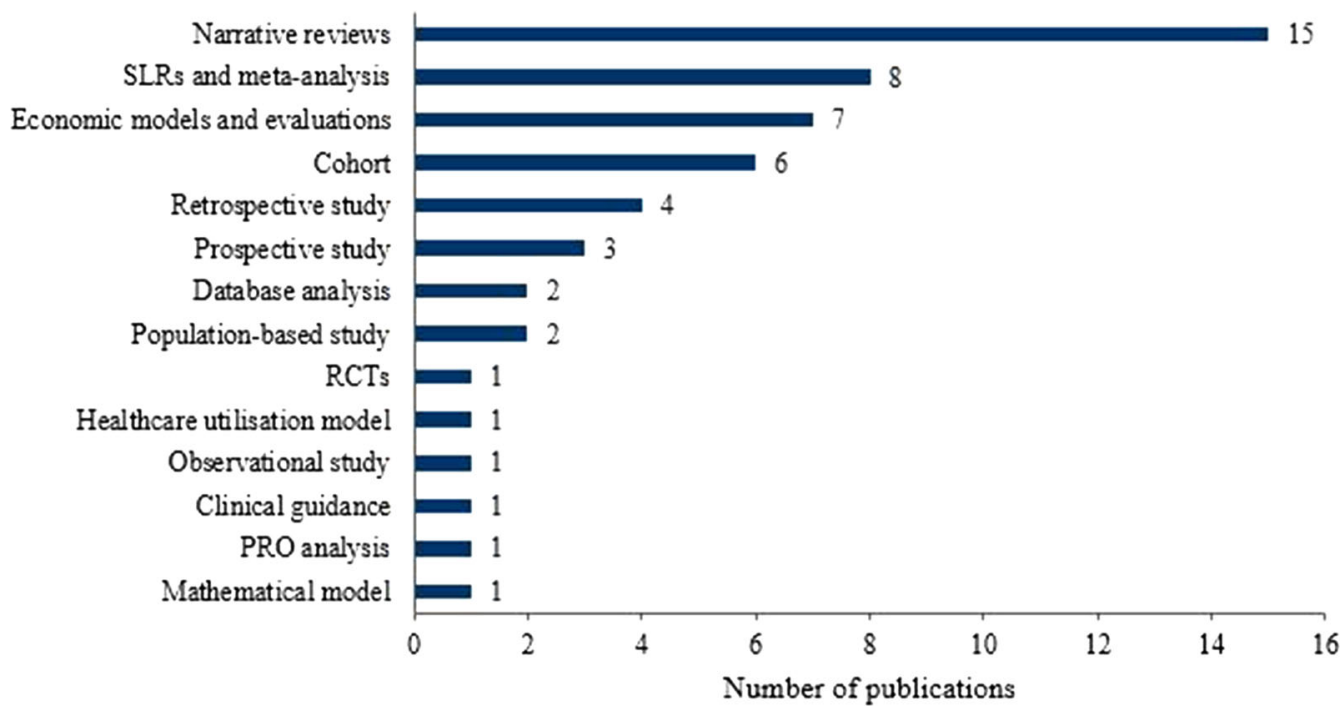

Fig. 2 Publications captured in the literature review by study type. $P R O$ patient-reported outcomes, $R C T$ randomized controlled trial, SLR systematic literature review

The majority of the 53 included publications were small cohort studies and narrative reviews. Several SLRs and economic models and evaluations were also reported (Fig. 2). The full list of captured publications is presented in Appendix B.

\section{NASH Prevalence and Incidence}

The overall NASH prevalence was reported in 13 publications [19-31]. NASH was estimated to affect between $3 \%$ and $5 \%$ of the global population, with minor variation at the countryspecific level; prevalence data were captured for the Chinese, Japanese, UK and USA populations (Fig. 3).

Over half of the publications primarily focused on the NAFLD population and employed a narrative review approach. The research focus varied across publications and different methodologies were used to determine NASH epidemiology; therefore, direct comparison of prevalence data was difficult. Of note, only four of the 13 prevalence publications specified the exact methodology. One population-based study used a validated histological 'NASH' score to estimate the NASH prevalence. The remaining three publications used data from annual health checks, national health surveys and autopsy results to estimate the prevalence of NASH $[24,26,28,29]$.

The epidemiology of NASH was reported in an SLR and meta-analysis which collated data from the USA, UK, France, Germany and Italy [19]. By computing the incidence, mortality and disease transition probability parameters in a series of interlinked Markov chains, it reported that the majority of NASH patients exhibit NASH without fibrosis (approximately 67\%), while up to $25 \%$ and $11 \%$ had fibrosis and cirrhosis, respectively [19]. These were also most common in the $65+$ age group, highlighting the progressive increase in disease burden in NASH [19].

Although NASH prevalence was reported frequently in the captured publications, no incidence data for NASH were found, highlighting a data gap.

\section{The NAFLD/NASH Continuum}

While several NAFLD-focused publications reported NASH prevalence in the general population, one publication reported on NAFLDspecific NASH prevalence [19]. In this SLR and meta-analysis, approximately $60 \%$ of biopsied NAFLD patients $(95 \%$ confidence interval (CI) 


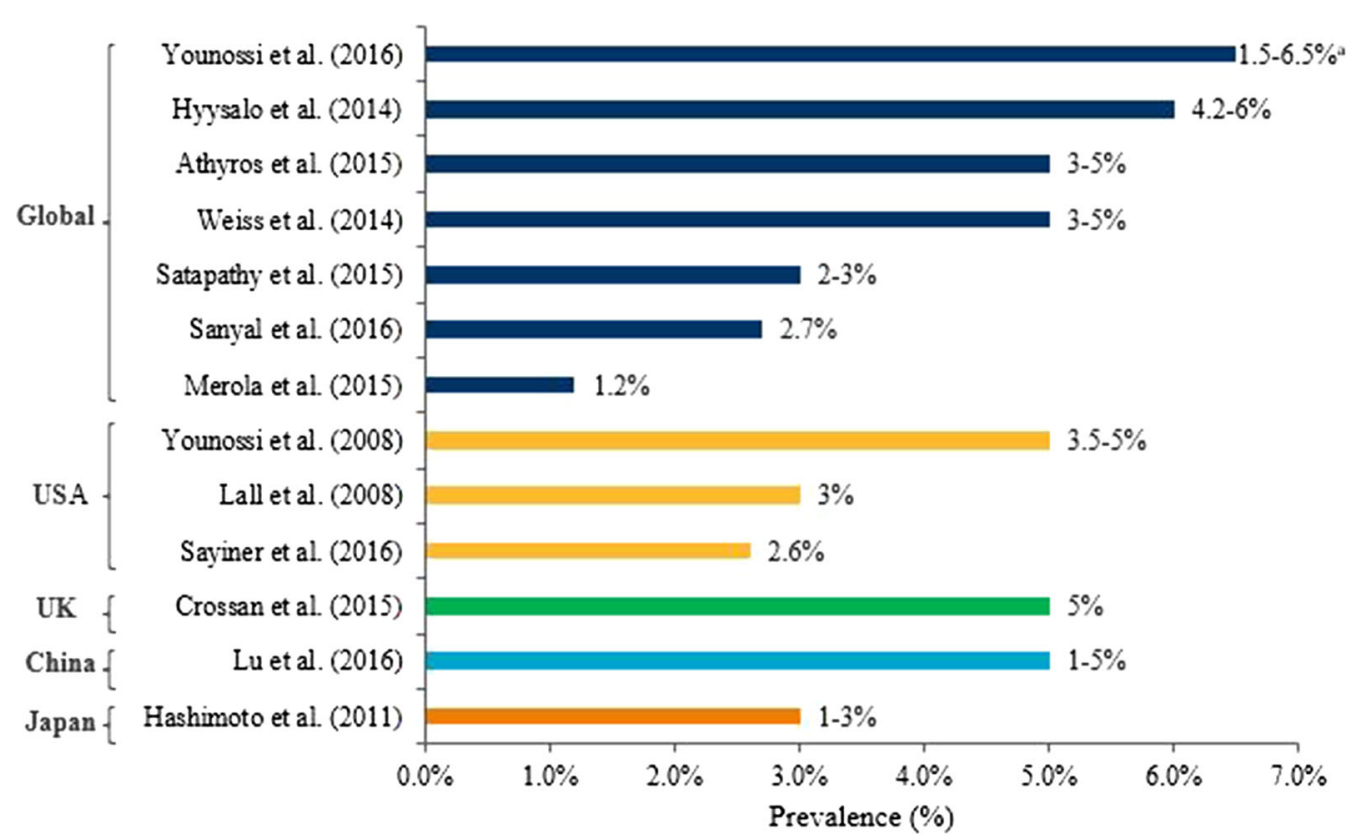

Fig. 3 Overall NASH prevalence in the general population. NASH non-alcoholic steatohepatitis, UK United Kingdom, USA United States. ${ }^{2}$ Values rounded to 1 decimal point

47.55-69.73) progressed to NASH [19]. However, the authors acknowledged there may be a selection and ascertainment bias in this estimate since indication for biopsy is typically conducted in NAFLD patients with a high risk of progressing to NASH. Further stratification of NASH prevalence was available for NAFLD patients with and without an indication for biopsy across Asia, Europe (EU) and North America. Although NASH prevalence was similar across regions (ranging from 63\% to 69\%), NASH was over four times more prevalent in NAFLD patients without indication for biopsy in North America (29.85\%; 95\% CI 22.72-38.12) compared to Asia $(6.67 \%$; $95 \%$ CI 2.17-18.73) [19].

\section{Comorbidities Associated with NASH}

Comorbidity data were the most frequently reported, with 18 publications describing obesity, diabetes and cardiovascular comorbidities in NASH patients (Table 1) $[19,21,22$, 24, 28-30, 32-42].

Overall, the prevalence of comorbidities associated with NASH was high, indicating a high disease burden and the burden of clinical management [19]. There was huge variability in the focus of the publications: some publications described the overall NASH population, whilst others focused on specific sub-populations, such as obese, diabetic, liver transplant (LT) and bariatric surgery patients. Consequently, findings were described as either a comorbidity prevalence in NASH or NASH prevalence in the comorbid sub-populations and, as such, a broad range of prevalence was reported. Variations in study methodologies meant that it was not possible to establish the correlation between these two types of prevalence reported; therefore, both are presented here (Table 1).

Risk factors for developing NASH were also reported, with female gender, over 50 years of age, diabetes, obesity, hyperlipidaemia/dyslipidaemia, hypertriglyceridaemia, metabolic syndrome and hypertension being reported as 
Table 1 NASH and comorbidities prevalence

\begin{tabular}{|c|c|c|c|c|c|}
\hline References & Type & Country & $\begin{array}{l}\text { Total } \\
\text { study size } \\
(n)\end{array}$ & Adult population & $\begin{array}{l}\text { Prevalence } \\
(\%)\end{array}$ \\
\hline \multicolumn{6}{|l|}{ NASH prevalence } \\
\hline Lall et al. [28] & Narrative review & USA & $\begin{array}{l}\text { Not } \\
\quad \text { reported }\end{array}$ & $\mathrm{NASH}$ in obese patients & $15-30$ \\
\hline \multirow[t]{2}{*}{ Mummadi et al. [33] } & Meta-analysis & USA & 766 & NASH in obese patients & 18.5 \\
\hline & & & & $\begin{array}{l}\text { NASH in morbidly obese } \\
\text { patients }\end{array}$ & 33 \\
\hline Estep et al. [43] & Cohort study abstract & $\begin{array}{l}\text { Not } \\
\text { reported }\end{array}$ & 44 & $\begin{array}{l}\text { NASH in obese bariatric } \\
\text { surgery patients }\end{array}$ & 75 \\
\hline \multirow[t]{2}{*}{ Hyysalo et al. [24] } & $\begin{array}{l}\text { Population-based } \\
\text { prevalence study }\end{array}$ & Finland & 676 & $\begin{array}{l}\text { NASH in obese bariatric } \\
\text { surgery patients aged } 45-74\end{array}$ & 14.5 \\
\hline & & & & $\begin{array}{l}\text { NASH in diabetic bariatric } \\
\text { surgery patients aged } 45-74\end{array}$ & 17 \\
\hline Athyros et al. [21] & Narrative review & Global & $\begin{array}{l}\text { Not } \\
\quad \text { reported }\end{array}$ & $\begin{array}{l}\text { NASH in morbidly obese } \\
\text { patients }\end{array}$ & 37 \\
\hline Losekann et al. [32] & Retrospective cohort study & Brazil & 250 & $\begin{array}{l}\text { NASH in morbidly obese } \\
\text { patients }\end{array}$ & 70.4 \\
\hline Sanyal et al. [30] & SLR abstract & Global & $\begin{array}{l}\text { Not } \\
\quad \text { reported }\end{array}$ & $\begin{array}{l}\text { NASH in obese bariatric } \\
\text { surgery patients }\end{array}$ & $34-94$ \\
\hline Sayiner et al. [29] & Narrative review & Global & $\begin{array}{l}\text { Not } \\
\quad \text { reported }\end{array}$ & $\begin{array}{l}\text { NASH in obese bariatric } \\
\text { surgery patients }\end{array}$ & $33.6-37$ \\
\hline Joshi et al. [41] & $\begin{array}{l}\text { Retrospective study } \\
\text { abstract }\end{array}$ & USA & 1920 & $\begin{array}{l}\text { NASH in type } 2 \text { diabetic } \\
\text { patients }\end{array}$ & 38 \\
\hline $\begin{array}{l}\text { Institute for Clinical } \\
\text { and Economic } \\
\text { Review [42] }\end{array}$ & $\begin{array}{l}\text { Evidence review and } \\
\text { comparative clinical } \\
\text { effectiveness analysis }\end{array}$ & USA & $\begin{array}{l}\text { Not } \\
\quad \text { reported }\end{array}$ & $\begin{array}{l}\text { NASH in type } 2 \text { diabetic } \\
\text { patients }\end{array}$ & $63-87$ \\
\hline \multicolumn{6}{|l|}{ Obesity prevalence } \\
\hline \multirow[t]{5}{*}{ Younossi et al. [19] } & SLR and meta-analysis & Global & $8,515,431$ & Obesity in NASH patients & $81.8^{\mathrm{a}}$ \\
\hline & & $\mathrm{EU}$ & & Obesity in NASH patients & $89.2^{\mathrm{a}}$ \\
\hline & & Oceania & & Obesity in NASH patients & $95.2^{\mathrm{a}}$ \\
\hline & & $\begin{array}{l}\text { South } \\
\text { America }\end{array}$ & & Obesity in NASH patients & $45.5^{\mathrm{a}}$ \\
\hline & & $\begin{array}{l}\text { North } \\
\text { America }\end{array}$ & & $\begin{array}{l}\text { Obesity in NASH patients } \\
\text { without indication for } \\
\text { biopsy }\end{array}$ & 80 \\
\hline
\end{tabular}


Table 1 continued

\begin{tabular}{|c|c|c|c|c|c|}
\hline References & Type & Country & $\begin{array}{l}\text { Total } \\
\text { study size } \\
(n)\end{array}$ & Adult population & $\begin{array}{l}\text { Prevalence } \\
(\%)\end{array}$ \\
\hline Sanyal et al. [30] & SLR abstract & Global & $\begin{array}{l}\text { Not } \\
\text { reported }\end{array}$ & Obesity in NASH patients & $31-89$ \\
\hline
\end{tabular}

\section{Type 2 diabetes prevalence}

Promrat et al. [40]

Simons et al. [39] Cohort study abstract $\quad$ USA 324

VanWagner et al. Cohort study abstract $\quad$ USA 6932

Estep et al. [43] Cohort study abstract

No

reported

44

eported

McPherson et al. Cohort study

UK

448

USA

5057

VanWagner et al.

Database analysis [37]

Losekann et al. [32] Retrospective cohort study

Brazil

250

Younossi et al. [19]

SLR and meta-analysis

Global

$8,515,43$

USA

650

abstract

Sanyal et al. [30]

SLR abstract

USA

Not

reported

Type 2 diabetes in NASH 48

Type 2 diabetes in NASH LT 77 patients

Type 2 diabetes in NASH LT 46.2 patients

Type 2 diabetes in obese

$20.3^{\mathrm{b}}$

$\mathrm{NASH}$ bariatric surgery patients

Type 2 diabetes in NASH 56

\section{CVD prevalence}

Vilar-Gomez et al. Prospective cohort study

Cuba

Not

CVD in $\mathrm{NASH}$ patients

2

[34]

Barritt et al. [44]

Observational study

USA

reported

\section{Hyperlipidaemia prevalence}

$\begin{array}{lll}\text { Estep et al. [43] Cohort study abstract } & \text { Not } & 44 \\ & \text { reported } & \end{array}$

Vilar-Gomez et al. Prospective cohort study Cuba [34]

Younossi et al. [19] SLR and meta-analysis

Global

1441

CVD in $\mathrm{NASH}$ patients

$9.4^{\mathrm{d}}$

ype 2 diabetes in NASH LT $\quad 57.1$ patients

Type 2 diabetes in morbidly $9^{c}$ obese diabetic NASH patients

Type 2 diabetes in NASH $\quad 43.6^{\mathrm{a}}$

Type 2 diabetes in NASH 45

Type 2 diabetes in NASH $\quad 5.3-73.1$

(1)

5


Table 1 continued

\begin{tabular}{|c|c|c|c|c|c|}
\hline References & Type & Country & $\begin{array}{l}\text { Total } \\
\text { study size } \\
(n)\end{array}$ & Adult population & $\begin{array}{l}\text { Prevalence } \\
(\%)\end{array}$ \\
\hline Sanyal et al. [30] & SLR abstract & USA & $\begin{array}{l}\text { Not } \\
\text { reported }\end{array}$ & $\begin{array}{l}\text { Hyperlipidaemia in NASH } \\
\text { patients }\end{array}$ & $16.9-86.2$ \\
\hline
\end{tabular}

\section{Hypertension prevalence}

$\begin{array}{llll}\text { Estep et al. [43] } & \text { Cohort study abstract } & \begin{array}{l}\text { Not } \\ \text { reported }\end{array} \\ & & \text { USA } & 5057\end{array}$

$\begin{array}{lll}\text { VanWagner et al. } & \text { Database analysis } & \text { USA }\end{array}$

Younossi et al. [19] SLR and meta-analysis

Sanyal et al. [30] SLR abstract

\section{Metabolic syndrome prevalence}

Hyysalo et al. [24]

$$
\begin{aligned}
& \text { Population-based } \\
& \text { prevalence study }
\end{aligned}
$$

Merola et al. [22] Clinical review

Younossi et al. [19] SLR and meta-analysis

Sanyal et al. [30] SLR abstract

\section{Hypercholesterolaemia prevalence}

Sanyal et al. [30] SLR abstract

\section{Hypertriglyceridaemia prevalence}

Younossi et al. [19] SLR and meta-analysis

Finland $\quad 676$

USA

Global

USA

Not reported

$8,515,431$

Not reported

USA Not Hypercholesterolaemia in 90.2 NASH bariatric surgery patients aged 45-74

Metabolic syndrome in

$40-60$ NASH LT patients

Metabolic syndrome in $\mathrm{NASH}$ patients

Metabolic syndrome in NASH patients

7.5-92.7

Global
$8,515,431$ $3.4^{\mathrm{g}}$

$70.7^{\mathrm{a}}$ NASH patients $40.7^{\mathrm{a}}$
Hypertension in obese NASH $28.5^{\mathrm{f}}$
bariatric surgery patients

35.7

$68^{a}$

$20.2-85.7$

Hypercholesterolaemia in

CVD cardiovascular disease, EU Europe, $L T$ liver transplant, $N A S H$ non-alcoholic steatohepatitis, $R C T$ randomized controlled trial, SLR systematic literature review, UK United Kingdom, USA United States

a Values rounded to 1 decimal point

b Calculated $27 \times 0.75=20.3 \%$, based on $75 \%$ of the population being NASH obese patients with bariatric surgery

c Calculated $12.8 \times 0.704=9 \%$, based on $70.4 \%$ of the population being NASH morbidly obese patients

d Calculated $20 \times 0.47=9.4 \%$, based on $47 \%$ of the population being diagnosed with NASH

e Calculated $31 \times 0.75=23.3 \%$, based on $75 \%$ of the population being NASH obese patients with bariatric surgery

f Calculated $38 \times 0.75=28.5 \%$, based on $75 \%$ of the population being NASH obese patients with bariatric surgery

g Calculated $57 \times 0.06=3.4$, based on $6 \%$ of the population being diagnosed with NASH 
specific factors increasing the risk of NASH $[19,22,26,29,35]$.

\section{Obesity}

The obesity prevalence in the NASH population was reported in two publications, ranging from $31 \%$ to $95 \%$ (Table 1 ) $[19,30]$. An SLR with a meta-analysis estimated that $82 \%$ of $\mathrm{NASH}$ patients suffer from obesity, with another SLR in broad agreement (estimated prevalence was between 31\% and 89\%); however, the authors cautioned that this range is likely influenced by the variable case definitions and methods used in individual studies examined in this review $[19,30]$. Obesity prevalence in NASH was also reported in different geographical regions, with obesity being twice as prevalent in NASH patients in the EU $(89.19 \%, 95 \%$ CI 74.51-95.88) and Oceania (95.24\%, 95\% CI 82.86-98.81) compared to South America (45.45\%, 95\% CI 26.47-65.86) [19].

NASH prevalence in the obese population was reported in seven publications and was more fragmented compared to obesity prevalence in NASH, largely due to the different populations of focus in the relevant publications (such as morbidly obese, obese, or bariatric surgery patients) [21, 24, 28-30, 32, 33]. NASH prevalence ranged from $15 \%$ to $94 \%$, depending on the population examined (Table 1), with prevalence in obese and morbidly obese patients reported as $15-30 \%$ and
$33-70 \%$, respectively $[21,28,33]$. NASH prevalence in the obese population with bariatric surgery was between $34 \%$ and $94 \%[29,30]$. Obese prevalence data were frequently reported for the global or USA populations, with one publication each focusing on Finnish and Brazilian NASH populations [24, 32].

\section{Type 2 Diabetes}

Type 2 diabetes prevalence in NASH was reported in ten publications [19, 30, 32, 35-40, 43]. An SLR and meta-analysis estimated the global diabetes prevalence among NASH patients to be $43.6 \%$ (Table 1) [19]. Similar results were presented in cohort studies (ranging between 33\% and 56\%) [34-36]. Another SLR reported a broader estimate of between $5 \%$ and $73 \%$; however, similarly to the obese population, the authors cautioned that the variable methods used in the captured studies have likely influenced these results [30]. The prevalence of diabetes was also reported in NASH LT patients and ranged between $46 \%$ and $77 \%$, suggesting an increased burden of diabetes LT patients [37-39].

NASH prevalence in the diabetic population was reported in three publications, ranging from $18 \%$ to $87 \%$ [24, 41, 42]. Although the NASH prevalence was higher in diabetics alone compared to diabetic bariatric surgery patients, the research focus of the captured publications varied substantially in terms of the geography,

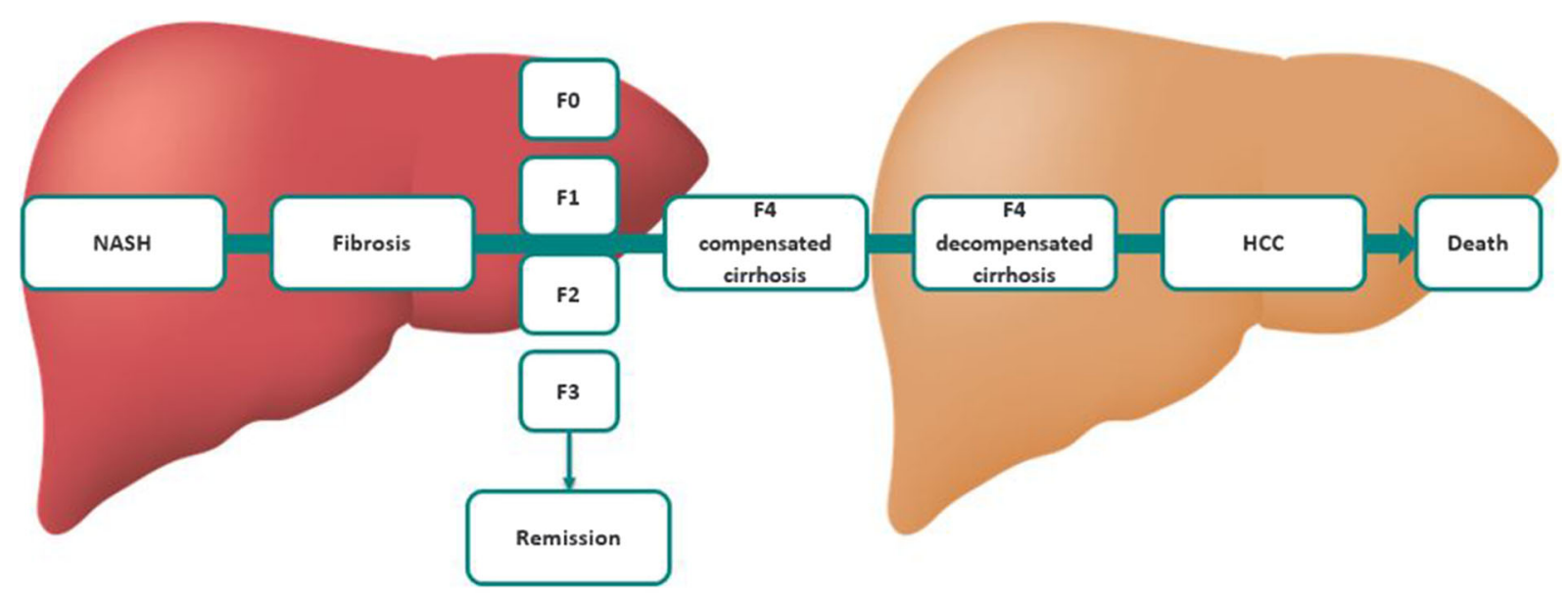

Fig. 4 NASH disease progression. F0/4 fibrosis stage 0/4, HCC hepatocellular carcinoma, NASH non-alcoholic steatohepatitis. Data adapted from Traussnigg et al. [44] 
with two publications focusing on the USA and one on Finland, and the type of population, such as NASH diabetic and NASH diabetic bariatric surgery patients, therefore making further meaningful comparisons impossible.

\section{Cardiovascular Disease}

Eight publications reported the prevalence of cardiovascular comorbidities in NASH patients, specifically focusing on hypercholesterolaemia, hyperlipidaemia, hypertension and metabolic syndrome (Table 1) $[19,22,24,30,34,37,43$, $44]$. Only two publications reported the overall cardiovascular disease (CVD) prevalence among NASH patients, which ranged from $2 \%$ to $20 \%$ $[34,44]$. A large SLR and meta-analysis reported the overall pooled prevalence for cardiovascular comorbidities among NASH patients as $72 \%$ for hyperlipidaemia/dyslipidaemia, $41 \%$ for hypertriglyceridaemia, $68 \%$ for hypertension and

Table 2 NASH progression to fibrosis

\begin{tabular}{|c|c|c|c|c|c|}
\hline References & Type & Country & $\begin{array}{l}\text { Total study } \\
\text { size }(n)\end{array}$ & NASH stage & Progression (\%) \\
\hline \multicolumn{6}{|c|}{ Progression from NASH to fibrosis } \\
\hline \multirow[t]{2}{*}{$\begin{array}{l}\text { Argo et al. } \\
\quad[46]\end{array}$} & \multirow[t]{2}{*}{ SLR } & \multirow[t]{2}{*}{ USA } & \multirow[t]{2}{*}{221} & $\begin{array}{l}\text { All NASH patients to stage } 3 / 4 \\
\text { fibrosis }\end{array}$ & $\begin{array}{l}15.8 \% \text { over } 3.7 \text { years } \\
\text { (mean interval) }\end{array}$ \\
\hline & & & & $\begin{array}{l}\text { NASH fibrosis patients who } \\
\text { progressed to stage } 3 / 4 \text { fibrosis }\end{array}$ & $\begin{array}{l}42.1 \% \text { over } 3.7 \text { years } \\
\text { (mean interval) }\end{array}$ \\
\hline $\begin{array}{l}\text { Musso et al. } \\
\text { [49] }\end{array}$ & Meta-analysis & $\begin{array}{l}\text { Not } \\
\text { reported }\end{array}$ & $\begin{array}{l}\text { Not } \\
\quad \text { reported }\end{array}$ & NASH to progressive fibrosis & $\begin{array}{l}25-30 \% \text { over } 4 \text { years } \\
50 \% \text { over } 6 \text { years }\end{array}$ \\
\hline $\begin{array}{l}\text { Sporea et al. } \\
{[54]}\end{array}$ & $\begin{array}{l}\text { Retrospective } \\
\text { cohort study }\end{array}$ & Romania & 478 & $\begin{array}{l}\text { NASH to severe fibrosis } \\
\text { NASH to no severe fibrosis }\end{array}$ & $\begin{array}{l}18.5 \%^{\mathrm{a}} \\
70.8 \%^{\mathrm{a}}\end{array}$ \\
\hline \multirow[t]{2}{*}{$\begin{array}{l}\text { Satapathy } \\
\text { et al. [23] }\end{array}$} & \multirow[t]{2}{*}{$\begin{array}{l}\text { Narrative } \\
\text { review }\end{array}$} & \multirow[t]{2}{*}{ USA } & \multirow[t]{2}{*}{$\begin{array}{l}\text { Not } \\
\text { reported }\end{array}$} & $\begin{array}{l}\text { NASH to fibrosis } \\
\text { NASH to F3 fibrosis }\end{array}$ & $\begin{array}{l}37 \%^{\mathrm{a}} \\
22 \%^{\mathrm{a}}\end{array}$ \\
\hline & & & & NASH to progressive fibrosis & $34.5 \%{ }^{\mathrm{a}}$ \\
\hline $\begin{array}{l}\text { Younossi } \\
\text { et al. [19] }\end{array}$ & SLR & USA & $8,515,431$ & NASH to fibrosis & $41 \%^{\mathrm{a}}$ \\
\hline $\begin{array}{l}\text { Shouhed } \\
\text { et al. [53] }\end{array}$ & $\begin{array}{c}\text { Narrative } \\
\text { review }\end{array}$ & USA & $\begin{array}{l}\text { Not } \\
\text { reported }\end{array}$ & NASH to fibrosis & $26-57 \%^{\mathrm{a}}$ \\
\hline
\end{tabular}

Progression from F1/F2 fibrosis onwards

Musso et al. Meta-analysis Sweden [49]
Not
reported

F1/2 fibrosis to cirrhosis

$13 \%^{\mathrm{a}}$

Progression from F3 fibrosis onwards

\begin{tabular}{|c|c|c|c|c|c|}
\hline $\begin{array}{l}\text { Musso et al. } \\
{[49]}\end{array}$ & Meta-analysis & Sweden & $\begin{array}{l}\text { Not } \\
\text { reported }\end{array}$ & $\begin{array}{l}\text { F3 fibrosis to cirrhosis and end stage } \\
\text { liver disease }\end{array}$ & $25 \%{ }^{\mathrm{a}}$ \\
\hline $\begin{array}{l}\text { Shouhed } \\
\text { et al. [53] }\end{array}$ & $\begin{array}{c}\text { Narrative } \\
\text { review }\end{array}$ & USA & $\begin{array}{l}\text { Not } \\
\text { reported }\end{array}$ & Fibrosis to cirrhosis & $9-17 \%^{\mathrm{a}}$ \\
\hline
\end{tabular}

F1/2/3/4 fibrosis stage 1/2/3/4, NASH non-alcoholic steatohepatitis, SLR systematic literature review, USA United States

a Time frame not reported 
$71 \%$ for metabolic syndrome [19]. This was in broad agreement with the wide range of prevalence (from $7.5 \%$ to $92.7 \%$ ) reported in another SLR [30]. Other publications reported a range of prevalence estimates, in line with the varying methodologies and population focus of the publications [22, 24, 34, 37, 43]. Small cohort studies and narrative reviews reported lower prevalence, specifically in sub-populations, such as NASH LT patients and NASH bariatric surgery patients $[22,24,34,37,43]$. As a result of fragmentation of the data and the less robust methodologies employed by these studies, no further conclusions could reliably be drawn.

\section{Disease Progression and Mortality in NASH Patients}

Disease progression and mortality was reported in 24 publications; fibrosis data were the most frequently reported, followed by cirrhosis and HCC [19-23, 26-28, 35, 37, 45-58]. Half of the publications were narrative reviews, while the other half ranged from small cohort studies to SLRs, highlighting a substantial range in the robustness of the data reported.

\section{Disease Progression in NASH}

As a result of a lack of effective diagnostic tools and nonspecific symptoms, NASH progression was difficult to establish. The majority of the publications did not specify the methodologies used to confirm disease progression; only a few utilized liver biopsies [19, 28, 46, 47].

The captured literature reported that up to $44 \%$ of patients with steatosis progress to NASH $[23,35]$. While early stages of NASH can be bidirectional (i.e. progression and regression can occur), the majority of patients (93\%) did not regress back to earlier stages of fibrosis (Fig. 4) [35].

Fibrosis Progression in NASH Several studies examining liver biopsy reported that approximately $40 \%$ of NASH patients progress to fibrosis globally [19, 28, 46, 47]. Global average annual progression of NASH to fibrosis was twice as fast as non-alcoholic fatty liver (NAFL) progression, corresponding to an average progression by one stage over 7.1 years versus 14.3 years, and highlighting the increase in the patient burden of NASH compared to NAFLD [23, 47].

An SLR of risk factors for fibrosis progression highlighted that the rate of progression increases in fibrosis patients compared to the overall NASH cohort, from 0.03 stages/year to 0.41 stages/year, respectively [46]. Inflammation on initial biopsy had a strongly significant predictive value for development of advanced fibrosis $(p<0.0001)$, with median time to progression to advanced fibrosis in patients with inflammation being 4.2 years versus 13.4 years in patients without inflammation [46].

In long-term follow-up over 5.3 years, most patients experienced no change in NASH severity; however, of the patients who did progress, approximately $70 \%$ advanced one stage and approximately $32 \%$ progressed two or more stages [46]. The authors concluded that between $5 \%$ and $10 \%$ of patients with NASH diagnosed on their initial biopsy will present with clinically significant fibrosis at this initial biopsy, and an additional $15-20 \%$ will progress to advanced fibrosis in less than a decade, emphasizing the progressive burden of NASH advanced fibrosis [46].

Progression between NASH fibrosis stages was also described in the evidence base. Progression between any fibrosis stages was reported in $16-71 \%$ of NASH patients, progression from $\mathrm{F} 1 / \mathrm{F} 2$ onwards in $9-13 \%$, and from F3 onwards in $9-25 \%$ of patients (Table 2) $[19,23,46,49,53,54]$. It is important to highlight that the publications reporting fibrosis stage progression utilized different stage terminology, e.g. F0-F4, stage 1/4, progressive fibrosis, advanced fibrosis, severe fibrosis, etc. The definitions for these stages were not always clarified; therefore, the comparability of these results was limited.

Cirrhosis and HCC Progression in NASH Cirrhosis and HCC progression were reported in ten publications $[19,20,22,23,26,27,45,50$, $51,55]$. In the captured publications, up to $25 \%$ of NASH patients progressed to liver cirrhosis and HCC [20, 22, 27, 45]. 
The prevalence of cirrhosis progression was reported as significantly higher in NASH patients compared to NAFL patients $(10.8 \%$ versus $0.7 \%$, respectively) [50]. A model of simulated NASH patient life course examined the average time of progression to decompensated cirrhosis and HCC for every NASH fibrosis stage, and the simulated average time to progress from early stage fibrosis (F1/F2) was longer (approximately 16 years) than the time to progress from advanced fibrosis (approximately 10 years) [55]. This highlighted the long-term clinical outcomes and increased mortality risk related to NASH progression [55].

HCC incidence was reported in three publications; however, this was reported as three distinct types of incidence: global cumulative incidence $(2.4 \%$ over 7 years and $12.8 \%$ over 3 years), global annual incidence $[5.29$ per 1000 patient years (95\% CI $0.75-37.56)]$ and incidence in Japan (between 5\% and 25\% during approximately 7 years) $[23,26]$. As the incidence type varied between publications, no robust comparisons could be made across these data.

An increased burden of NASH progression was acknowledged, highlighting that the rate of HCC progression is expected to increase faster than other hepatic diseases, such as hepatitis B or C. Consequently there are important implications for resource utilization, given that HCC has emerged as the sixth most common cancer and second leading etiology of cancer-related deaths worldwide [19]. A healthcare utilization model was in accord with this, predicting a disproportionate increase in NASH by 2030: the prevalences of compensated and decompensated cirrhosis cases were projected to increase $180 \%$ and $200 \%$ from 2015 to 2030 , respectively [51]. The number of NASH-related HCC cases was also projected to reach 12,220 cases in 2030, an increase of approximately $140 \%$ compared to 2015 [51].

\section{Mortality in NASH}

Fifteen publications reported mortality outcomes in NASH patients $[20-23,26,28,37$, $46,48-50,55-58]$. Several publications outlined an increased risk of death in NASH compared to the general population and patients with NAFL, and decreased survival compared to NAFLD patients [20, 28, 48, 49].

The overall mortality rate in NASH was 25.56 per 1000 patient years, with the liver-specific mortality rate reported as 11.77 per 1000 patient years [20]. An SLR and meta-analysis reported liver disease as the main cause of death in NASH, with a liver-related mortality rate of $11-17.5 \%$ compared to $1.7-2.7 \%$ of NAFLD (pooled odds ratio (OR) $5.71 ; 95 \%$ CI 2.31-14.13; $p=0.0002$ ) [49]. However, this was disputed in several narrative reviews, which reported CVD and malignancies as the main cause of death in NASH patients [20, 23, 57]. These publications reported the cause of death using several different measurements and across different populations; therefore, a selection bias may have been present.

NASH Fibrosis Mortality There was a significant worsening of mortality outcomes reported with advanced fibrosis (F3/F4) in NASH. Fibrosis progression was linked to a $70 \%$ increase in total mortality, compared with patients without fibrosis [21]. NASH patients with moderate-tosevere fibrosis at baseline also showed a worse survival rate compared to patients with mild fibrosis or no fibrosis (adjusted hazard ratio (HR) 2.09, $p=0.01)$ [21].

In addition, a model on the life course of $\mathrm{NASH}$ patients predicted that the long-term liver-related mortality and survival in NASH is worsened with fibrosis progression over 15 years [55]. This aligned with a previously conducted SLR and meta-analysis, which showed that advanced fibrosis increases liver-related mortality almost fivefold compared to mild fibrosis [49].

NASH Cirrhosis and HCC Mortality An increased mortality burden was also reported with NASH cirrhosis. NASH cirrhosis patient life expectancy was lower than non-cirrhotic NASH patients, with cirrhotic patients' survival ranging from $59 \%$ to $84 \%$ of the life expectancy of those without cirrhosis [26, 46, 50]. Median survival in NASH cirrhosis patients was approximately 6 years; they had a similar liverrelated mortality compared to viral cirrhosis and a higher CVD-related mortality was 
observed [49]. Annual mortality rates for patients with compensated cirrhosis and decompensated cirrhosis specifically were $2 \%$ and $13 \%$, respectively, demonstrating a higher mortality burden with progressive worsening of cirrhosis [58].

There was a paucity of HCC mortality data, reported in only two publications $[26,50]$. The 5-year survival of NASH HCC was reported as $44.8 \%$, with HCC being one of the leading causes of death in NASH patients $(47 \%$ of deaths), representing an independent risk factor for liver-related mortality (HR 7.96) $[26,50]$.

\section{NASH QoL}

There was a paucity of data reporting on QoL, specifically on patient-reported outcomes (PRO), with only three publications identified [59-61]. The following experiences were captured in the search: only one generic PRO instrument, the Short Form-36 (SF-36) health survey and one liver-specific questionnaire, the Chronic Liver Disease Questionnaire (CLDQ) reported BoD data [59-61].

Two publications reported on NASH patients experiencing poorer physical and mental health compared to non-NASH patients according to the SF-36 scale, with significantly poorer scores in NASH patients compared to non-NASH patients in mental health, physical functioning, role limitations due to emotional health and social function ( $p<0.05$ for all) $[59,60]$. These findings were confirmed via the CLDQ instrument, which revealed additional impairments in all domains (abdominal symptoms, fatigue, systemic symptoms, activity, emotional function, worry) associated with a reduced overall CLDQ score $(p<0.0001$ for all $)[60,62]$. The presence of diabetes $[p=0.04$ for Physical Component Score (PCS)] was the only demographic/clinical variable reported that was associated with impaired health-related quality of life (HRQoL) amongst NASH patients [60]. The authors concluded that CLDQ was a reliable and valid measurement tool of disease-specific HRQoL in adults with NASH.

\section{NASH Economic Burden}

NASH economic burden was reported in 12 publications [30, 42, 58, 63-70].

The majority of the publications were health economic evaluations, with the cost-effectiveness of NASH screening methods and treatments the most reported-on economic outcome. However, there was a paucity of data on the societal costs or the healthcare burden of $\mathrm{NASH}$ with only one meta-analysis reporting on the direct costs of NASH [63].

Advanced fibrosis progression was associated with significant increases in costs [63]. In all stages of NASH, direct medical costs were reported to be high using prevalence-based simulation modelling techniques: in 2016 the total burden was estimated to be $\$ 103$ billion per year in the USA versus $€ 27.7$ billion in France, Germany and Italy together and $£ 5.24$ billion in the UK [63]. NASH patients with compensated cirrhosis presented the highest direct cost burden compared to patients in other stages of $\mathrm{NASH}$, highlighting the cost burden of advanced NASH progression.

Direct medical costs were also examined per age group, with total costs highest in patients aged 45-65, mirroring the disease prevalence [63]. However, per patient costs were reported as highest in the $65+$ age group, reflecting the higher proportion of patients in advanced fibrosis and HCC, and the increased burden of comorbidities [63]. A USA SLR and model confirmed the high economic burden of NASH, reporting that the total cost of NASH-related care in North America will amount to \$593 billion between 2013 and 2033 [30].

Lastly, a USA database analysis reported on high costs of NASH hospitalizations, with hospitalizations related to CVD incurring a longer stay and higher associated financial cost compared to NAFLD hospitalizations unrelated to CVD (length of stay was 6.5 versus 5.3 days, $p<0.001$; hospitalization cost was $\$ 57,534$ versus $\$ 44,007, p<0.001)[52,70]$. 


\section{DISCUSSION}

To the authors' knowledge, this structured literature review is the first broad-ranging examination of the NASH epidemiology, BoD literature, QoL and economic burden literature. In total, 53 publications were included in this review, with a significant paucity of data observed across all aspects of NASH epidemiology. The publications presented varying study designs and methodologies; the majority of the publications were small cohort studies (sample sizes of less than or equal to 100) and narrative reviews with undefined methodologies, while only a few publications employed a robust systematic approach. As a result, comparison of the results was difficult. Eight SLRs were captured in this review; however, only two examined the BoD in NASH $[19,25,30,31,33,46,47,49]$. The high impact BoD SLR and meta-analysis study by Younossi et al. was underpinned by a model forecasting NASH prevalence and incidence [19]. The other BoD SLR by Sanyal et al. presented limited information on NASH prevalence, comorbidities and economic burden as the study was only available in abstract form [30]. Compared to the available literature identified, the current structured literature review provides a robust methodology and a more recent examination of data, with a broader scope, including NASH QoL and disease progression.

NASH was estimated to account for $3-5 \%$ of the global population, and approximately $60 \%$ of biopsied NAFLD patients [19-29]. Prevalence data are essential in understanding the size of current and future NASH populations; however, the captured publications presented a range of prevalence data, likely due to the varying publication focus and robustness of the methodologies used. Over half of the captured publications employed a narrative review approach and most did not specify the methodology used, reflecting the poor quality of these publications.

As a result of the unreliability of liver biopsy in diagnosing NASH and its association with high costs and invasive nature, especially in the general population, NASH prevalence data cannot be retrieved accurately and were frequently estimated [14]. Validated 'histological' NASH score, data from annual health checks, national health surveys, and autopsy results were used in the identified publications to estimate the prevalence of NASH; however, these data can be fragmented and subject to selection bias, specifically in higher burden population, who likely also have one or more comorbid conditions, e.g. advanced fibrosis patients will likely have a higher instance of obesity and CVD compared to mild fibrosis patients. To ensure that accurate prevalence data are obtained not only from patients but also from the general public, an accurate, non-invasive and cost-effective screening tool is needed. For instance, ultrasound screening has emerged as a promising screening technique that is non-invasive, accurate and widely available [31, 67-69, 71]. Blood-based biomarkers have also emerged as a promising diagnostic alternative in NASH as they are non-invasive, have rapid turnaround times and pose limited risks to patients [72]. More research on biomarkers in $\mathrm{NASH}$ is needed to determine if these markers accurately reflect disease progression in NASH and can be implemented in clinical practice [72].

The global burden of NASH is high, with clinical consequences extending beyond the liver. Approximately $80 \%$ of NASH patients suffer from at least one comorbidity, with obesity, diabetes and CVD being the most common [19]. While it is unclear to what extent NASH development is linked to these conditions, it is clear that NASH association with these comorbidities increases both the patient and healthcare burden $[19,21,22,24,28-30,32-42]$. Despite this, the specific prevalence of comorbidities in NASH remains unclear with substantial discrepancies in the literature, specifically in sub-populations, such as in obese, morbidly obese, or bariatric surgery patients. For instance, NASH prevalence in a diabetic population was $14.5 \%$ in one study, and between $63 \%$ and $87 \%$ in a different study on the diabetic population $[41,42]$. This can be due to several reasons, e.g. different baseline populations, or different definitions of how NASH is estimated/measured. Specifically, the varied 
focus of the publications was a key factor in the discrepancies noted, and a selection bias could have affected these results. This was further compounded by the robustness of the methodologies used, as the majority of the publications consisted of small cohort or observational studies.

On the basis of the current evidence base, it is unclear whether the BoD in NASH stems primarily from comorbidities or from NASH directly. For example, when comparing the QoL in patients with NASH, of which $27 \%$ have diabetes and $28 \%$ had bridging fibrosis or cirrhosis, to diabetic patients alone, the SF-36 PCS scores of patients with NASH and diabetes (mean 44.5) are lower than those with diabetes (mean 49.8), suggesting that the disease severity is worse in NASH and that comorbidities add to the overall burden of disease [59, 73]. However, when comparing the QoL in patients with NASH, of which $19 \%$ had diabetes and $37 \%$ had hypertension, to heart failure patients alone, the SF-36 PCS scores (mean 44.2) are higher than for those with heart failure (mean 36.5), suggesting that the burden of NASH is mostly dependent on the comorbidities [60, 74]. As a result of the limited QoL data in NASH patients and the different patient populations described, the true role of comorbidities in NASH BoD remains unclear. Further research is required to clarify the relationship between NASH and its comorbidities before firm conclusions can be drawn.

Despite the limited conclusions gathered from the literature on comorbidities in NASH, data on NASH progression were numerous [19-23, 26-28, 35, 37, 45-58]. The results clearly showed that NASH with advanced fibrosis significantly increases the likelihood of further progression to cirrhosis and HCC, with one in five NASH patients developing cirrhosis and/or HCC. While mild fibrosis (F1/F2) frequently presents with nonspecific symptoms and low disease burden, advanced fibrosis (F3/F4) exponentially reduces survival and increases liverrelated mortality, with an approximately sevenfold increase in mortality rate in NASH compared to NAFLD $[50,55]$. NASH, specifically NASH with advancing fibrosis, therefore presents itself as a clear target for future pharmacological therapies aiming at reducing the burden of NAFLD and its complications. Despite this, not all published literature is in agreement that NASH should be the main target of NAFLD therapy: a recent retrospective study of 60 NAFLD patient biopsies by Hagström et al. reported that baseline steatohepatitis was not associated with an increased risk for fibrosis progression in NAFLD and that fibrosis progression can occur in NAFLD patients without steatohepatitis [75]. In contrast, a multinational prospective study of 458 NAFLD patients by Vilar-Gomez et al. reported that steatosis is significantly associated with a higher risk of death and liver-related complications, which aligns with the findings of this review, showcasing that NASH is associated with a significant burden and poor long-term prognosis [76]. It is important to note that because the exact cause of NAFLD and NASH is not yet understood, it is difficult to accurately assess the underlying factors for progression [5-7]. Therefore, further research into the cause of this disease is recommended to improve our understanding of disease progression and the key factors at play.

Understanding of disease progression in NASH was impeded by the lack of consistency in fibrosis and cirrhosis stage terminology reported. Several terminologies were used in NASH staging, which were frequently unexplained in the publications and some appeared subjective, e.g. advanced cirrhosis, severe fibrosis and progressive fibrosis. Therefore, to ensure that the progression of NASH to a highly burdensome advanced fibrosis stage is clearly understood, a consensus on staging terminology is required. Correct terminology will allow for a clear quantification of the true disease burden of each step of this progressive disease and supports the development of effective therapies, specifically in advancing fibrosis, which has presented itself as a key determinant of disease progression and mortality [46].

There was a significant lack of NASH QoL data, with only three publications reporting on PROs in NASH [59-61]. NASH patients reported significantly poorer physical and mental health, impacting the quality of their daily lives $[59,60]$. Only the SF-36 health survey and CLDQ were reported, with standardized liver 
disease PROs, such as CLDQ, considered most appropriate. In order to truly understand the burden of this disease, however, patient-relevant outcomes, as well as clinical outcomes, must be further researched.

NASH-specific economic burden data, and especially in relation to direct costs of NASH, were lacking in the literature $[30,63,70]$. The most prevalent economic data described NASH screening and treatment strategies, indicating an interest in new diagnostic tools and appropriate therapies, but a lack of research into their exact costs. The publications that investigated direct costs of NASH reported that, despite presenting with little or no symptoms, NASH association with comorbidities and its progressive nature significantly impacts healthcare systems in terms of costs. One meta-analysis reported that disease progression to cirrhosis and beyond was associated with significant increases in costs [63]. Additionally, NASH cirrhosis patients exhibited significantly higher rates of hospitalizations compared with other cirrhosis etiologies. While several publications briefly reported on the economic burden of NASH specifically, few reported explicit costs. When costs were reported, they were not defined, e.g. "direct costs" were used but no clarification of what these costs included was provided. This is likely because there are little patient-level data available and cost databases frequently do not report NASH diagnosis, rather reporting liver disease or NAFLD with fibrosis or cirrhosis. This makes any information on NASH costs difficult to establish or compare; thus, the exact economic burden of NASH remains unclear.

Therapy options in NASH were not a focus of this review, and very few papers specifically looking at the economic impact of management options were retrieved. This is likely a reflection of no licensed drugs currently being available for NASH. At present, NASH management is varied and many off-label treatment options are being utilised in routine practice [77-81]. Current treatment focuses primarily on lifestyle modification and disease management, including weight loss, dietary modifications, exercise and managing comorbidities [79-81]. Many investigational treatments are being researched with more than 150 interventional studies currently ongoing (as described by clinicaltrials.gov) [82]. Although advanced fibrosis is associated with the highest morbidity and mortality burden in NASH, there is a lack of treatments targeting NASH patients with advanced fibrosis with only two current therapies showing improvements in this population [81]. Further investigational therapies are needed for NASH with advanced fibrosis, given that the majority of the available and upcoming NASH therapies are primarily focused on patients with mild-to-moderate fibrosis [81].

\section{Limitations}

A number of limitations were noted during the course of this structured literature review. The focus of this review was the NASH population, and as such the NAFLD population was not explicitly included in the search strategy. As NASH is the progressive phenotype of NAFLD, it is likely that some NAFLD publications with NASH information were excluded on the basis of this criterion. However, as publications reporting on NASH by name (even as part of the larger NAFLD population) were included, excluded publications would have likely not focused on NASH and may not have presented any discrete results other than for the overall NAFLD population.

Another limitation was the restriction of this structured review to English language publications. Despite a third of the included publications reporting data on non-English speaking countries, it is possible that some eligible publications were not captured because of this exclusion.

Additionally, a sparse evidence base was found across all stages of NASH, with several limitations identified in the captured literature. The publications consisted of generally poorquality small studies, with short follow-up times, lack of consistency in describing NASH staging, variations in individual study aims, highly selective populations or differing geographies. As NASH is frequently reported as part of the wider NAFLD burden and is often not clearly distinguished from NAFLD, this may 
explain the small amount of studies focusing on NASH specifically and the poor quality of the literature identified in this review.

\section{CONCLUSION}

This first broad-ranging structured examination of the NASH literature revealed a paucity of evidence, which likely reflects the absence of approved therapies. As a result of its nonspecific symptoms and progressive nature, NASH remains underdiagnosed and poorly understood despite its high patient burden. Fibrosis is the key prognostic factor in NASH, with a worse prognosis observed in advanced fibrosis. The overwhelming impact of advanced fibrosis on patients and healthcare systems is evident. There is a clear need for early detection in $\mathrm{NASH}$, particularly among symptomatic patients, along with the need for lifestyle modifications alongside new therapies. Important knowledge gaps remain in the literature, including a clear understanding of NASH progression and its association with comorbidities, NASH patient QoL and NASH-specific economic burden. Further robust quality evidence, specifically real-world and clinical trial data, is needed to improve our understanding of NASH, especially as fibrosis stages advance and NASH burden increases. This will inform the development of effective therapies in NASH and improve the management of this highly burdensome disease.

\section{ACKNOWLEDGEMENTS}

Funding. This study was funded by Gilead Science Inc and was conducted by Adelphi Values Limited. All authors were involved in drafting the article and revising it critically for important intellectual content, and all authors approved the final version to be published. The sponsor also funded the article processing charges and Open Access fee for this article.

Authorship. All named authors meet the International Committee of Medical Journal
Editors (ICMJE) criteria for authorship for this article, take responsibility for the integrity of the work as a whole, and have given their approval for this version to be published.

Disclosures. Juliana Bottomley is a consultant to Gilead Sciences Inc and received consultancy payment for her contract. Adelphi Values Limited received budgetary compensation for involvement in the conduct of the literature review and manuscript development. Richard Perry is an employee of Adelphi Values Limited. Manca Povsic is an employee of Adelphi Values Limited. On Yee Wong is an employee of Adelphi Values Limited.

Compliance with Ethics Guidelines. This article is based on previously conducted studies and does not contain any studies with human participants or animals performed by any of the authors.

Data Availability. Data sharing is not applicable to this article as no databases were generated or analysed during the current study.

Open Access. This article is distributed under the terms of the Creative Commons Attribution-NonCommercial 4.0 International License (http://creativecommons.org/licenses/ by-nc/4.0/), which permits any noncommercial use, distribution, and reproduction in any medium, provided you give appropriate credit to the original author(s) and the source, provide a link to the Creative Commons license, and indicate if changes were made.

\section{REFERENCES}

1. Takahashi Y, Fukusato T. Histopathology of nonalcoholic fatty liver disease/nonalcoholic steatohepatitis. World J Gastroenterol. 2014;20(42): 15539-48.

2. European Medicines Agency. Reflection paper on regulatory requirements for the development of medicinal products for chronic non-infections liver disease (PBC, PSC, NASH); 2018. https://www.ema. europa.eu/documents/scientific-guideline/reflecti on-paper-regulatory-requirements-development- 
medicinal-products-chronic-non-infectious-liver_ en.pdf. Accessed 26 Nov 2018.

3. National Institute of Diabetes and Digestive and Kidney Diseases. Symptoms and causes of NAFLD and NASH; 2016. https://www.niddk.nih.gov/ health-information/liver-disease/nafld-nash/ symptoms-causes. Accessed 12 Oct 2018.

4. Corte CD, Ferrari F, Villani A, Nobili V. Epidemiology and natural history of NAFLD. J Med Biochem. 2015;34(1):13-7.

5. Wegermann K, Diehl AM, Moylan CA. Disease pathways and molecular mechanisms of nonalcoholic steatohepatitis. Clin Liver Dis. 2018;11(4): 87-91.

6. Tarantino G, Porcu C, Arciello M, Andreozzi P, Balsano C. Prediction of carotid intima-media thickness in obese patients with low prevalence of comorbidities by serum copper bioavailability. J Gastroenterol Hepatol. 2018;33(8):1511-7.

7. Liu $\mathrm{P}, \mathrm{Xu} \mathrm{Y}$, Tang $\mathrm{Y}$, et al. Independent and joint effects of moderate alcohol consumption and smoking on the risks of non-alcoholic fatty liver disease in elderly Chinese men. PLoS One. 2017;12(7):e0181497.

8. Madrazo B. Diagnosis of nonalcoholic steatohepatitis without liver biopsy. Gastroenterol Hepatol (N Y). 2017;13(6):378-80.

9. Allen A, Van Houten H, Sangaralingham L, Talwalkar J, McCoy R. Healthcare cost and utilization in nonalcoholic fatty liver disease: real-world data from a large U.S. claims database. Hepatology. 2018;68:2230-8.

10. NHS. Non-alcoholic fatty liver disease (NAFLD). 2018. https://www.nhs.uk/conditions/non-alcoho lic-fatty-liver-disease/. Accessed 10 Oct 2018.

11. Estes C, Razavi H, Loomba R, Younossi Z, Sanyal A. Modeling the epidemic of nonalcoholic fatty liver disease demonstrates an exponential increase in burden of disease. Hepatology. 2018;67(1):123-33.

12. Perumpail B, Khan M, Yoo E, Cholankeril G, Kim D, Ahmed A. Clinical epidemiology and disease burden of nonalcoholic fatty liver disease. World J Gastroenterol. 2017;23(47):8263-76.

13. Ekstedt M, Nasr P, Kechagias S. Natural history of NAFLD/NASH. Curr Hepatol Rep. 2017;16(4):391-7.

14. Filozof C, Goldstein BJ, Williams RN, Sanyal A. Non-alcoholic steatohepatitis: limited available treatment options but promising drugs in development and recent progress towards a regulatory approval pathway. Drugs. 2015;75(12):1373-92.
15. Hardy T, Anstee QM, Day CP. Nonalcoholic fatty liver disease: new treatments. Curr Opin Gastroenterol. 2015;31(3):175-83.

16. Cusi K. Treatment of patients with type 2 diabetes and non-alcoholic fatty liver disease: current approaches and future directions. Diabetologia. 2016;59(6):1112-20.

17. European Liver Patient's Association. NASH and NAFLD-lifestyle related conditions as the new European public health challenge; 2017. http:// www.elpa.eu/news/jun-2017/nash-and-nafld-life style-related-conditions-new-european-public-hea lth-challenge. Accessed 10 Oct 2018.

18. The Cochrane Collaboration. Cochrane handbook for systematic reviews of interventions; 2011. http://handbook-5-1.cochrane.org/.

19. Younossi Z, Koenig A, Abdelatif D, Fazel Y, Henry L, Wymer M. Global epidemiology of nonalcoholic fatty liver disease-meta-analytic assessment of prevalence, incidence, and outcomes. Hepatology. 2016;64(1):73-84.

20. Weiss J, Rau M, Geier A. Non-alcoholic fatty liver disease. Dtsch Ärztebl Int. 2014;111:447-52.

21. Athyros V, Tziomalos K, Katsiki N, Doumas M, Karagiannis A. Cardiovascular risk across the histological spectrum and the clinical manifestations of non-alcoholic fatty liver disease: an update. World J Gastroenterol. 2015;21(22):6820-34.

22. Merola J, Liapakis A, Mulligan D, Yoo P. Non-alcoholic fatty liver disease following liver transplantation: a clinical review. Clin Transpl. 2015;29: 728-37.

23. Satapathy S, Sanyal A. Epidemiology and natural history of nonalcoholic fatty liver disease. Semin Liver Dis. 2015;35(3):221-35.

24. Hyysalo J, Männistö V, Zhou Y, et al. A populationbased study on the prevalence of NASH using scores validated against liver histology. J Hepatol. 2014;60:839-46.

25. Lu W, Li S, Li J, et al. Effects of omega-3 fatty acid in nonalcoholic fatty liver disease: a meta-analysis. Gastroenterol Res Pract. 2016;2016:1-11.

26. Hashimoto E, Tokushige K. Prevalence, gender, ethnic variations, and prognosis of NASH. J Gastroenterol. 2011;46(suppl 1):63-9.

27. Younossi Z. Review article: current management of non-alcoholic fatty liver disease and non-alcoholic steatohepatitis. Aliment Pharmacol Ther. 2008;28:2-12. 
28. Lall C, Aisen A, Basnal N, Sandrasegaran K. Nonalcoholic fatty liver disease. Am Roentgen Ray Soc. 2008;190:993-1002.

29. Sayiner M, Koenig A, Henry L, Younossi Y. Epidemiology of nonalcoholic fatty liver disease and nonalcoholic steatohepatitis in the United States and the rest of the world. Clin Liver Dis. 2016;20(2):205-14.

30. Sanyal A, Martin A, Cadarette S, et al. A systematic literature review of the epidemiology and economic burden associated with non-alcoholic steatohepatitis. J Hepatol. 2016;64:S475.

31. Crossan C, Tsochatzis E, Longworth L, et al. Costeffectiveness of non-invasive methods for assessment and monitoring of liver fibrosis and cirrhosis in patients with chronic liver disease: systematic review and economic evaluation. Health Technol Assess. 2015;19(9):1366-5278.

32. Losekann A, Weston A, de Mattos A, et al. Nonalcoholic steatohepatitis (NASH): risk factors in morbidly obese patients. Int $\mathrm{J}$ Mol Sci. 2015;16:25552-9.

33. Mummadi RR, Kasturi KS, Chennareddygari S, Sood GK. Effect of bariatric surgery on nonalcoholic fatty liver disease: systematic review and meta-analysis. Clin Gastroenterol Hepatol. 2008;6(12):1396-402.

34. Vilar-Gomez E, Martinez-Perez Y, Calzadilla-Bertot L, et al. Weight loss through lifestyle modification significantly reduces features of nonalcoholic steatohepatitis. Gastroenterology. 2015;149:267-378.

35. McPherson S, Hardy T, Henderson E, Burt A, Day C, Anstee Q. Evidence of NAFLD progression from steatosis to fibrosing-steatohepatitis using paired biopsies: implications for prognosis and clinical management. J Hepatol. 2015;62:1148-55.

36. Mantry P, Mehta A, Hess P, et al. Ethnic diversity at presentation in patients with NASH: data from a tertiary referral center. In: Paper presented at: 3rd world congress on hepatitis and liver diseases; 10-12 Oct, 2016; Dubai, UAE.

37. VanWagner L, Lapin B, Skaro A, Lloyd-Jones D, Rinella M. Impact of renal impairment on cardiovascular disease mortality after liver transplantation for nonalcoholic steatohepatitis cirrhosis. Liver Int. 2015;35(12):2575-83.

38. Van Wagner L, Lapin B, Lloyd-Jones B, Skaro A, Rinella M. Early cardiovascular disease mortality after liver transplantation-is nonalcoholic steatohepatitis (NASH) to blame? In: Paper presented at American Association for the Study of Liver Diseases; 7-11 Nov, 2014; Boston, Massachusetts.
39. Simons S, Forde K, Li Y, Reddy K, Bahirwani R. Cardiovascular disease in liver transplant candidates with NASH/cryptogenic cirrhosis. In: Paper presented at American Association for the Study of Liver Diseases; 1-5 Nov, 2013; Washington, DC.

40. Promrat K, Kleiner DE, Niemeier HM, et al. Randomized controlled trial testing the effects of weight loss on nonalcoholic steatohepatitis. Hepatology. 2010;51(1):121-9.

41. Joshi K, Thakkar J, Boron A, et al. The prevalence of non-alcoholic steatohepatitis among diabetic patients followed by primary care and endocrinology. J Hepatol. 2016;64:S486.

42. Institute for Clinical and Economic Review. Obeticholic acid for the treatment of nonalcoholic steatohepatitis: comparative clinical effectiveness and value-evidence report; 2016.

43. Estep JM, Greer A, Mehta R, et al. Sa1357 histologic $\mathrm{NASH}$ is associated lack of improvement of metabolic conditions post bariatric surgery. Gastroenterology. 2014;146(5):271.

44. Barritt S. Nonalcoholic fatty liver disease in the U.S.: clinical characteristics of patients enrolled in TARGET-NASH. In: Paper presented at American Association for the Study of Liver Diseases; 2017.

45. Traussnigg S, Kienbacher C, Halilbasic E, et al. Challenges and management of liver cirrhosis: practical issues in the therapy of patients with cirrhosis due to NAFLD and NASH. Dig Dis. 2015;33(4):598-607.

46. Argo C, Northup P, Al-Osaimi A, Caldwell S. Systematic review of risk factors for fibrosis progression in non-alcoholic steatohepatitis. J Hepatol. 2009; 51(2):371-9.

47. Singh S, Allen A, Wang Z, Prokop L, Murad M, Loomba R. Fibrosis progression in nonalcoholic fatty liver vs nonalcoholic steatohepatitis: a systematic review and meta-analysis of paired-biopsy studies. Clin Gastroenterol Hepatol. 2015;13(4): 643-54.

48. Soderberg C, Stål P, Askling J, et al. Decreased survival of subjects with elevated liver function tests during a 28-year follow-up. Hepatology. 2010;51(2): 595-602.

49. Musso G, Gambino G, Cassader M, Pagano G. Metaanalysis: natural history of non-alcoholic fatty liver disease (NAFLD) and diagnostic accuracy of noninvasive tests for liver disease severity. Ann Med. 2011;43:617-49. 
50. Marengo A, Jouness R, Bugianesi E. Progression and natural history of nonalcoholic fatty liver disease in adults. Clin Liver Dis. 2015;20(2):313-24.

51. Estes C. Burden of nonalcoholic fatty liver disease (NAFLD) in the United States. In: Paper presented at American Association for the Study of Liver Diseases; 11-15 Nov, 2016; Boston, Massachusetts.

52. Ergelen R, Yilmaz Y, Asedov R, et al. Comparison of Doppler ultrasound and transient elastography in the diagnosis of significant fibrosis in patients with nonalcoholic steatohepatitis. Abdom Radiol. 2016;41:1505-10.

53. Shouhed D, Steggerda J, Burch M, Noureddin M. The role of bariatric surgery in nonalcoholic fatty liver disease and nonalcoholic steatohepatitis. Expert Rev Gastroenterol Hepatol. 2017;11(9):1-15.

54. Sporea I, Jurchiş A, Şirli R, Bota S, Şendroiu M. Can transient elastography be a reliable method for assessing liver fibrosis in non alcoholic steatohepatitis (NASH)? Med Ultrason. 2013;15(2):106-10.

55. Samur S. Long-term clinical outcomes and mortality related to nonalcoholic steatohepatitis: predictions of a mathematical model. In: Paper presented at American Association for the Study of Liver Diseases; 2017.

56. Sadler E, Mehta N, Bhat M, et al. Liver transplantation for hepatocellular carcinoma in non-alcoholic steatohepatitis (NASH) compared to nonNASH patients. In: Paper presented at European Society for Organ Transplantation; 24-27 Sept, 2017; Barcelona, Spain.

57. Ahmed A, Wong RJ, Harrison SA. Nonalcoholic fatty liver disease review: diagnosis, treatment, and outcomes. Clin Gastroenterol Hepatol. 2015;13(12):2062-70.

58. Corey K, Klebanoff M, Tramontano A, Chung R, Hur C. Screening for nonalcoholic steatohepatitis in individuals with type 2 diabetes: a cost-effectiveness analysis. Dig Dis Sci. 2016;61(7):2108-17.

59. David K, Kowdley K, Unalp A, Kanwal F, Brunt E, Schwimmer J. Quality of life in adults with nonalcoholic fatty liver disease: baseline data from the NASH CRN. Hepatology. 2009;49(6):1904-12.

60. Chawla K, Talwalkar J, Keach J, Malinchoc M, Lindor K, Jorgensen R. Reliability and validity of the Chronic Liver Disease Questionnaire (CLDQ) in adults with non-alcoholic steatohepatitis (NASH). BMJ Open Gastroenterol. 2016;3:1-6.

61. Kennedy-Martin T BJ, Paczkowski R, Freeman E. A review of the quality life burden non-alcoholic steatohepatitis. In: Paper presented at ISPOR 22nd annual international meeting; 20-24 May, 2017; Boston, Massachusetts.

62. The NASH Education Program; 2018. https://www. the-nash-education-program.com/what-is-nash/. Accessed 10 Oct 2018.

63. Younossi Z, Blissett D, Blissett R, et al. The economic and clinical burden of nonalcoholic fatty liver disease in the United States and Europe. Hepatology. 2016;64(5):1577-86.

64. Chalasani N, Younossi Z, Lavine JE, et al. The diagnosis and management of nonalcoholic fatty liver disease: practice guidance from the American Association for the Study of Liver Diseases. Hepatology. 2018;67:328-57.

65. Mahady S, Wong G, Craig J, George J. Pioglitazone and vitamin $\mathrm{E}$ for nonalcoholic steatohepatitis: a cost utility analysis. Hepatology. 2012;56:2172-9.

66. Klebanoff MJ, Corey KE, Chhatwal J, Kaplan LM, Chung RT, Hur C. Bariatric surgery for nonalcoholic steatohepatitis: a clinical and cost-effectiveness analysis. Hepatology. 2017;65(4):1156-64.

67. Zhang E, Wartelle-Bladou C, Lepanto L, Lachaine J, Cloutier G, Tang A. Cost-utility analysis of nonalcoholic steatohepatitis screening. Eur Radiol. 2015;25(11):3282-94.

68. Tanajewski L, Harris R, Harman D, et al. Economic evaluation of a community based diagnostic pathway to stratify adults for non-alcoholic fatty liver disease: a Markov model informed by a feasibility study. Br Med J. 2017;7:e015659.

69. Phisalprapa P, Supakankunti P, Charatcharoenwitthaya $\mathrm{P}$, et al. Cost-effectiveness analysis of ultrasonography screening for nonalcoholic fatty liver disease in metabolic syndrome patients. Medicine. 2017;96(17):1-8.

70. Jinjuvadia R, Liangpunsakul S, Salgia R. Hospitalizations related to cardiovascular disease and cardiac procedures among patients with nonalcoholic steatohepatitis. In: Paper presented at American Association for the Study of Liver Diseases Abstracts; 13-15 Nov, 2015; San Francisco, California.

71. Corey K, Rinella M. Medical and surgical treatment options for nonalcoholic steatohepatitis. Dig Dis Sci. 2016;61(5):1387-97.

72. Francque S, Vonghia L. The future of diagnosing NASH-could a simple blood test be the key? Expert Rev Gastroenterol Hepatol. 2017;11(11):995-7.

73. Norris S, Zhang $\mathrm{X}$, Chowdhury $\mathrm{F}$, et al. Health related quality of life measured by SF-36 for adults 
with diabetes: a meta-analysis. In: Abstracts of the 12th Cochrane Colloquium, 2-6 Oct, 2004, Ottawa; Canada.

74. Huber A, Oldridge N, Hofer S. International SF-36 reference values in patients with ischemic heart disease. Qual Life Res. 2016;25(11):2787-98.

75. Hagström $\mathrm{H}$, Elfwen $\mathrm{O}$, Hultcrantz R, Stal P. Steatohepatitis is not associated with an increased risk for fibrosis progression in nonalcoholic fatty liver disease. J Gastroenterol Res Pract. 2018;2018:7.

76. Vilar-Gomez E, Calzadilla-Bertot L, Wai-Sun Wong $\mathrm{V}$, et al. Fibrosis severity as a determinant of causespecific mortality in patients with advanced nonalcoholic fatty liver disease: a multi-national cohort study. Gastroenterology. 2018;155(2):443-457 e417.

77. Banini BA, Sanyal AJ. Current and future pharmacologic treatment of nonalcoholic steatohepatitis. Curr Opin Gastroenterol. 2017;33(3):134-41.

78. Ratziu V, Goodman Z, Sanyal A. Current efforts and trends in the treatment of NASH. J Hepatol. 2015;62(1 Suppl):S65-75.
79. Sumida Y, Yoneda M. Current and future pharmacological therapies for NAFLD/NASH. J Gastroenterol. 2018;53(3):362-76.

80. Oseini AM, Sanyal AJ. Therapies in non-alcoholic steatohepatitis (NASH). Liver Int. 2017;37(Suppl 1):97-103.

81. Povsic M, Louisa O, Jiandani N, Perry R, Bottomley J. A structured literature review of interventions used in the management of non-alcoholic steatohepatitis (NASH). pharmacol Res Perspect. 2019. (in print).

82. ClinicalTrials.gov; 2019. https://clinicaltrials.gov/ ct2/results?cond=Non+Alcoholic + Steatohepatitis\& recrs $=a \&$ recrs $=$ f\&recrs $=d \& a g e \_v=\& g n d r=\&$ type $=I n$ tr\&rslt=\&Search=Apply. Accessed 4 Apr 2019.

83. Carruthers J, Bottle A, Laverty A, Khan S, Millett C, Vamos E. Nation-wide trends in non-alcoholic steatohepatitis (NASH) in patients with and without diabetes between 2004-05 and 2014-15 in England. Diabetes Res Clin Pract. 2017;132:102-7. 